\title{
Sea surface salinity reconstruction as seen with foraminifera shells: Methods and cases studies
}

\author{
B. Malaizé and T. Caley \\ Université Bordeaux 1, UMR 5805 EPOC, Avenue des Facultés, 33405 Talence, France
}

\begin{abstract}
Reconstruction of past salinities in surface oceans (SSS) can be done by measuring the isotopic composition of foraminifera shells found in the deep sea sediments. The proportion of heavy oxygen isotopes $\left({ }^{18} \mathrm{O}\right)$ in the calcite of these shells depend on the temperature and the isotopic oxygen composition of the surrounded waters $\left(\delta^{18} \mathrm{Osw}\right)$, this latter parameter depending on the water salinity. Mainly two equations allows to reconstructed past SSS, one estimating past temperature variations and the other one changes in the $\delta^{18} \mathrm{Osw}$ through time. Uncertainties linked with these calculation can be important, and therefore quantitative reconstructions need to be taken with cautions. For some specific cases, uncertainties on temperature and $\delta^{18} \mathrm{Osw}$ estimations can be reduced. For such cases, salinity reconstructions showing amplitude changes higher than 1 per mil can be considered as significative.
\end{abstract}

\section{Introduction}

The role of salinity in oceanography is crucial: It plays an important part in the hydrography, i.e. intensities and directions of major current. As a main parameter in the oceanographic engine, it also contributes to heat transfert throughout ocean circulation, and therefore to regional and global climate changes.

To reconstruct past oceanographic conditions, scientists need to gather a huge compilation of data set (oceanic temperatures and salinities) over a long period of time and covering major parts of worldwide oceans. Furthermore, quantitative reconstructions of oceanic parameters are needed as inputs for oceanographic or climatic models. Some sea sediments displays interesting geologic archives, as long as its sedimentation process has not been disturbed, i.e. without any time gap or physical disruption (such as turbiditic flows on continental shelf or bioturbation). Microfossils of past oceanic life can be found in these archives, and their assemblages oftenly give indications on the conditions in which they developed, as for example mean sea surface temperatures (hereafter SST). Only few geological archives are known to be directly related to sea surface salinities (hereafter SSS), and therefore, some indirect method, based on foraminifera microfossils, have been developed to reconstruct past SSS. As long as some foraminifera species have specific living requirements, studies have investigated past SSS reconstructions based on foraminiferal abundance data. The use of Artificial Neural Network, or Modern Analog Technique, have led to the conclusion that such estimations were unrealistic [1], and can't be considered as quantitative. Therefore, scientists turned their attention to geochemical analysis of foraminifera species, which could lead to quantitative estimations of SSS.

The aim of this paper is to present an overview of past sea surface salinities reconstructions through the chemistry of foraminifera microfossils, to estimate uncertainties of such paleorecords, and to discuss wether it can be used as quantitative parameters or not. 


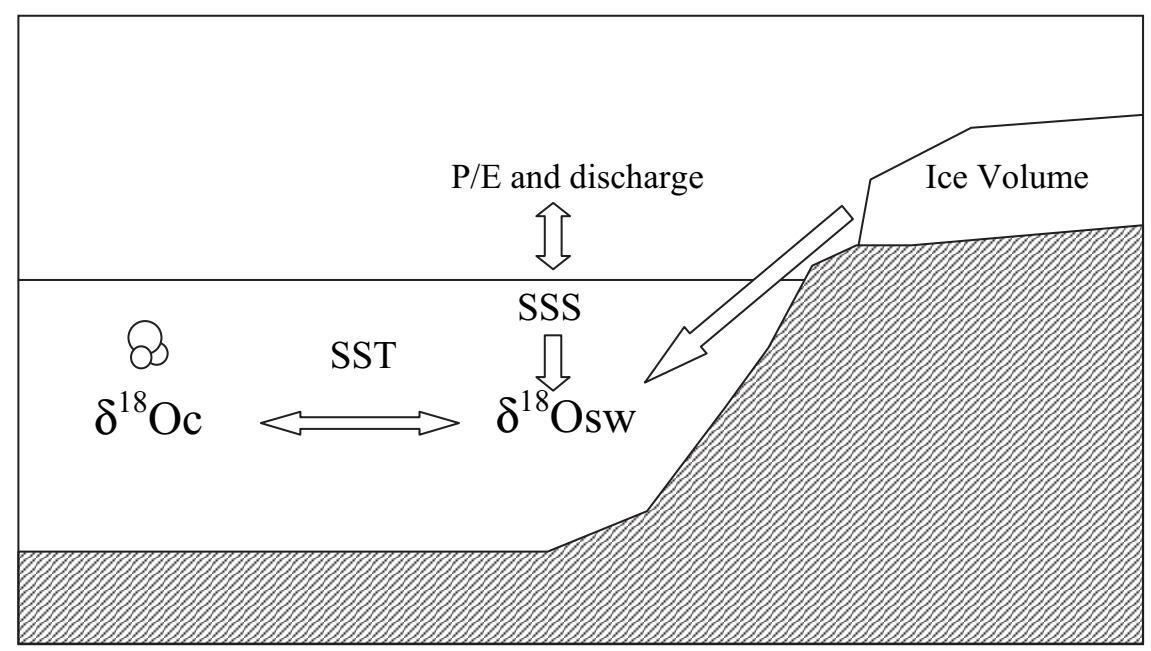

Fig. 1. Main parameters influencing the isotopic composition of planktonic foraminifera shells $\left(\delta^{18} \mathrm{Oc}\right)$ : Sea surface temperature (SST) and the isotopic composition of the surrounded waters $\left(\delta^{18} \mathrm{Osw}\right)$. This last parameter is also dependant on sea surface salinity (SSS), linked with the evaporation-precipitation balance $(\mathrm{P} / \mathrm{E})$ and with the volume of continental ice sheets (depleted in heavy isotopes).

\section{Stable isotopes fractionation in foraminifera shells}

\subsection{Today}

Marine invertebrates such as foraminifera are building exoskeletons made of calcium carbonate to protect themselves from predators. Isotopic fractionations are taking place during this process, depending on both the proportion of stable isotopes available in the waters surrounding the foraminifera and the temperature of these waters (Figure 1). Many experimental and theoretical studies have been held since the middle of last century to understand the incorporation of oxygen isotopes in foraminifera shells.

Epstein et al., in 1953, established a paleotemperature equation, linking the temperature with the isotopic composition of the calcite and of the surrounded waters [2]. Shackleton and Opdyke have adapted this equation in 1973 [2] into the following one:

$$
\mathrm{T}=16.9-4.38\left(\delta^{18} \mathrm{Oc}-\delta^{18} \mathrm{Osw}\right)+0.13\left(\delta^{18} \mathrm{Oc}-\delta^{18} \mathrm{Osw}\right)^{2}
$$

$\left(\delta^{18} \mathrm{Oc}\right.$ is the isotopic value of the calcite, and $\delta^{18} \mathrm{Osw}$ the isotopic composition of the sea water).

This relationship holds only if foraminifera deposit their shells in isotopic equilibrium with their growth medium. An overview of several oceanic sites revealed that only few species fits these requirements. Meanwhile, some quantitative temperature reconstructions seems to be possible.

This equation underlines the double dependance of the $\delta^{18} \mathrm{Oc}$ of the foraminiferal shell with temperature changes together with the marine isotopic composition changes $\delta^{18}$ Osw. We have one equation with two unknowned. To complicate the solving, $\delta^{18} \mathrm{Osw}$ is also dependent on salinity changes. A first overview of experimental measurements, made in 1965, following a series of observations made during oceanic cruises over different oceans (top cores), allows Craig and Gordon to established a first salinity-water isotope relationship (Figure 2) [4]:

$$
\delta^{18} \mathrm{Osw}=0.66 \mathrm{SSS}-23.5 .
$$

Since this pioneer work, many other observations have shown a wide range of slopes, depending on oceans, and on the nature of these waters (deep or shalow). These descrepancies will be discussed in a following section. 


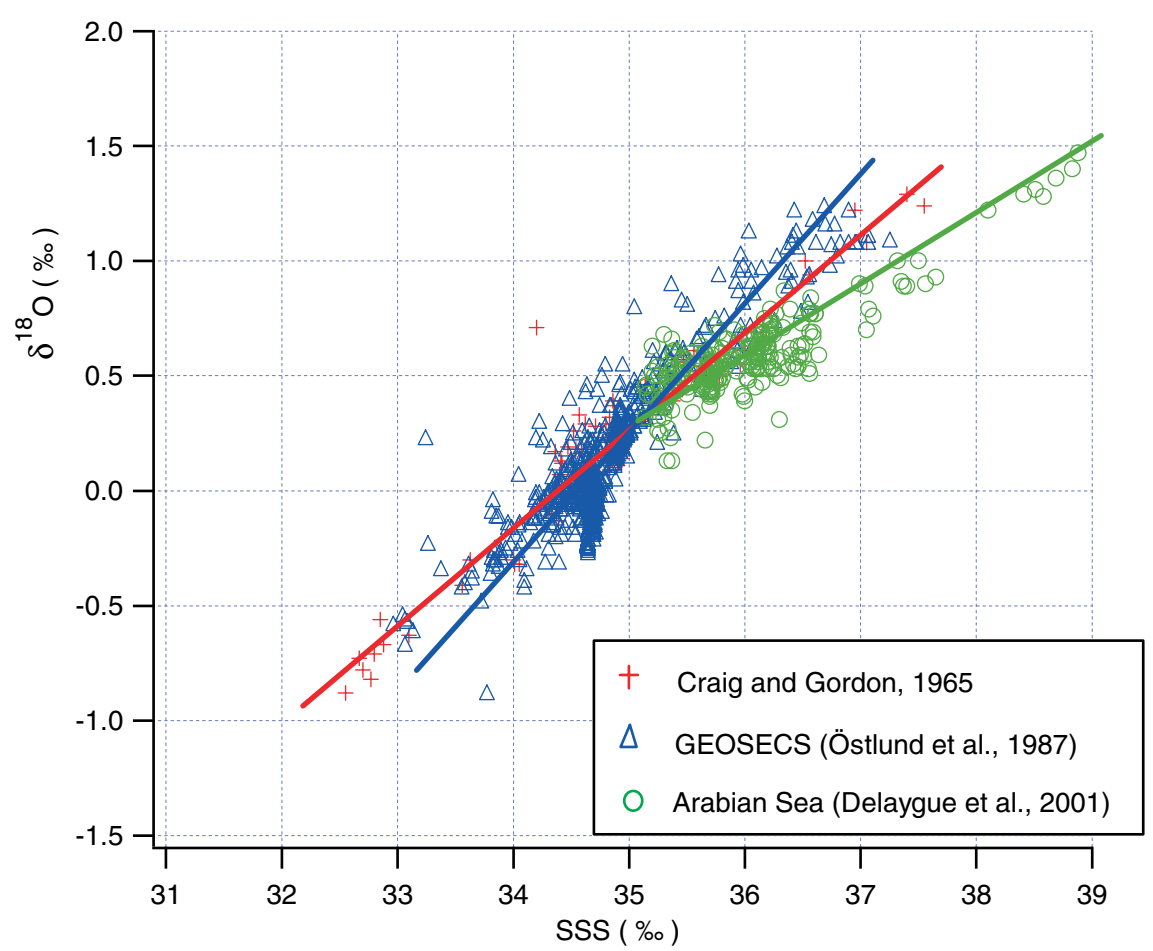

Fig. 2. Different $\delta^{18}$ Osw-salinity relationships deduced from two different data sets of the worldwide oceans [4] from GEOSECS cruises [24], and from modeled output gathered with observed data from the Arabian Sea [36]. Data compiled by Gavin Schmidt [25], http://data.giss.nasa.gov/o18data/.

To conclude, the $\delta^{18} \mathrm{Oc}$ of a monospecific species of foraminifera is directly dependent on the temperature, but also undirectly dependent on the salinity which follows the $\delta^{18}$ Osw. Equations (1) and (2) were build using specific foraminifera species, within a certain range of temperature and salinity. They could be applied only for some specific situation.

Within these requirements and according to equations (1) and (2), salinity reconstruction can be done using the estimations of two different oceanic parameters: Sea surface temperatures and $\delta^{18} \mathrm{Osw}$ values. This latter term can be evaluated with the resolution of equation (1), with temperatures estimations and $\delta^{18} \mathrm{O}$ of the calcite of the foraminifera shell.

$$
\delta^{18} \mathrm{Osw}=\delta^{18} \mathrm{Oc}+0.27-5\left(4.38-\sqrt{ }\left(4.38^{2}-0.4(16.9-\mathrm{SST})\right)\right.
$$

(Factor 0.27 is added for calibration against international standard).

In fine, to calculate SSS, we are bounded to a system with two equations, $(2)+(3)$, and two unknowned parameters $\left(\delta^{18} \mathrm{Osw}\right.$ and SST). For today's measurements, no other equations are needed.

\subsection{Reconstruction of SSS in the past}

Today's observations are questionned to be applyed in the past. Emiliani et al. were the first to published an isotopic curve extracted from benthic and planctonic foraminifera in deep sea cores, which they interpreted in terms of past variations of climatic parameters [5]. Most of this signal has been interpreted in terms of paleotemperatures, but not much in terms of paleosalinities.

To estimate past SSS, three terms need to be taken into account:

1. Modification of global salinity due to global changes in continental ice sheet volume (i.e. $\left.\Delta \mathrm{SSS}_{\mathrm{G}-\mathrm{IG}}\right)$, which can be estimated with relative sea level changes. 
2. Modification of the local salinity due to regional changes in the hydrographic balance (linked with local SST)

3. Modification of the $\delta^{18} \mathrm{Osw}$ due to global changes in continental ice sheet. During deglaciation times, fresh water discharges coming from the melting of continental ice sheet invade oceans, changing their salinity and, as a consequence, their isotopic compositions.

The last two terms are contributing to changes in the local/global SSS (i.e. $\Delta$ SSS $_{\text {Loc-Glob). }}$ Adding these changes to present SSS allows to evaluate past SSS.

$$
\mathrm{SSS}_{\text {Past }}=\mathrm{SSS}_{\text {Present }}+\Delta \mathrm{SSS}_{\mathrm{G}-\mathrm{IG}}+\Delta \mathrm{SSS}_{\text {Loc-Glob }} .
$$

To calculate changes in SSS on a global and local scale $\left(\Delta \mathrm{SSS}_{\mathrm{Loc}-\mathrm{Glob}}\right)$, changes in temperatures and $\delta^{18} \mathrm{Osw}$ in the past need to be estimated.

If past variations in SST are easy to link with climatic changes, modification of the isotopic composition of sea waters might be a less straightforward reasoning.

On a global scale, the building of huge ice caps on the continent during glacial periods leads to an enrichment of the worldwide oceans in heavy ${ }^{18} \mathrm{O}$ isotopes (Figure 1). This enrichment is due to thermodynamic fractionation processes taking place during different stages of the hydrological cycle. Heavy isotopes concentrate more in densier phases, contributes to a stronger concentration of light isotopes in the continental ice, and, as a consequence, to a stronger concentration of heavier isotopes in oceans.

Glacial-interglacial changes lead to global salinities changes in the worldwide oceans (figure 1). As continental ice sheet are made with fresh water, the consequence is an increase of salinity in the ocean when entering a glacial period. If equation (2) stays valid in the past, the isotopic composition of the ocean should have changed in response to these salinity changes.

In addition to these artefact due to global effects (directly on $\delta^{18} \mathrm{Osw}$ and SSS), local changes could affect also specifically some part of the ocean. For example, climatic change could lead to some modifications in the balance between evaporation and precipitation over a studied area. Such changes might have contributed to modify locally salinity concentrations, and therefore the isotopic composition of the surface sea waters.

The problem is that no geological archive has directly recorded past $\delta^{18} \mathrm{Osw}$ values, on a local neither a global scale. One way to solve this apparent problem is to distinguish the planktonic isotopic record from the benthic isotopic record. Indeed, for some remoted and deep environments, benthic foraminifera are surrounded by waters for which temperature and salinity changes can be constrained. For these environments, for deep part of the Pacific ocean for example, some isotopic studies have focused on the estimation of deep water temperature changes and their imprint on the benthic isotopic signal. Adding some calibration to sea level changes, estimations of $\delta^{18} \mathrm{Osw}$ changes through glacial-interglacial periods can be done. Some scientists had compiled several benthic records from different deep oceanic areas where such estimations can be done. Some reference stacks of benthic records have been published, and linked to global sea level changes (Figure 3) [6-10].

Once these $\delta^{18} \mathrm{Osw}$ changes due to global effect have been estimated, $\delta^{18} \mathrm{Osw}$ changes due to local effect (past and present) need to be estimates. One way to solve this problem is to resolve equation (3), requiring estimation of past temperatures.

Difficulties to apply reliationships (3) and (2) in the past are numerous. For example, isotopic measurements need to be done on a well studied monospecific species, constantly present in time (no evolution) and defined to be in isotopic equilibrium (or showing a constant difference) with the standard water composition. Secondly, the reconstructed temperatures and salinities need to be within the range defined by equations.

\section{SST estimations: Solving equation (3)}

For the first tentative of sea surface temperature reconstructions, faunistic assemblages of foraminifera species have been developped. The first study which succeed in reconstructing SST is the pionneer work by Imbrie and Kipp in 1971 [11], laying the foundation stone to many 


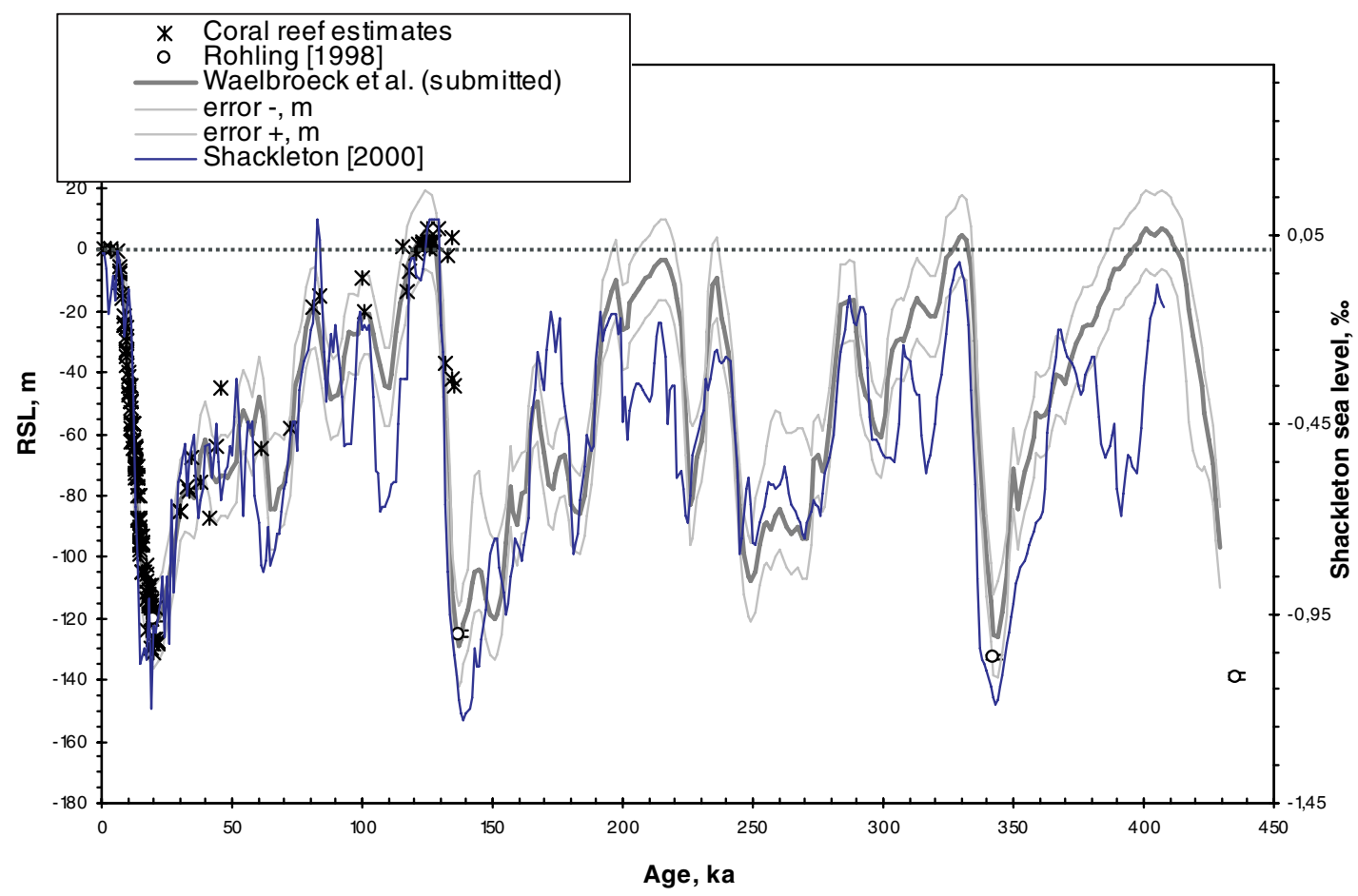

Fig. 3. Sea level reconstruction and consequent global $\delta^{18}$ Osw changes through time [6-8].

'transfert function' applied since then to other proxies. The purpose is to compare present-day distribution of foraminifera to oceanic temperature distribution, and to extract the most representative species of specific temperature intervals. Some other technics have been developed since this first study [12], as the Modern Analogue Technic (MAT) for example. Application of these reconstructions to the last glacial maximum climatic conditions led to different maps showing SST distributions for this specific time period, as for example the CLIMAP project [13], or the more recent MARGO project [14]. The best reconstructions are able to reproduce temperature within $\mathrm{a}+/-1.3^{\circ} \mathrm{C}$ uncertainties intervals [12].

Another way to reconstruct surface temperature is to look at today's distribution of the difference between $\delta^{18} \mathrm{Osw}$ and $\delta^{18}$ Ocalcite, and then to apply equation (1). Duplessy et al. presented the first SSS reconstruction, mixing previous transfert fonction SST estimates together with statistical analysis of isotopic measurements made on 83 core tops from North Atlantic and Southern Oceans [15]. The authors pointed out different calibrations of calcification temperature, depending on each studied species. For $G$. bulloides, a $1^{\circ} \mathrm{C}$ difference is observed between summer SST and the calcification temperature, although $2.5^{\circ} \mathrm{C}$ difference is due for $N$. pachyderma. This study underlines one main difficulty in such reconstruction, for which the calcification temperature depends on the foraminifera species.

Recently, geochemistry development has proposed a new technic to estimate SST via individual foraminifera species analysis, removing uncertainties in equation (1) due to $\delta^{18} \mathrm{Osw}$ changes through time, linked to either global or local changes. Theoretically, $\mathrm{Mg}^{2+}$ alkaline element can replace $\mathrm{Ca}^{2+}$ element in the rhombohederal structure of the calcite. Thermodynamic predictions, along with experimental observations, have demonstrated a major temperature control on the distribution coefficient [16-20]. For foraminifera species, some calibrations were needed to estimate the biological effect on this partitioning. Culture studies, as well as sediment trap sample studies, led to a similar exponential dependence calibration for different planktonic species [21]:

$$
\mathrm{Mg} / \mathrm{Ca}\left(\text { mmolmol-1) }=\mathrm{B} \cdot \mathrm{e}^{\mathrm{A} \cdot \mathrm{T}}\right.
$$


Table 1. Adapted from LeGrande and Schmidt 2006.

\begin{tabular}{|c|c|c|c|c|c|c|}
\hline Water Mass & Total points & Slope & Intercept & $\sigma$ slope & $\sigma$ intercept & $\mathbf{r}^{2}$ \\
\hline Arctic Ocean & 1846 & 0.48 & -16.82 & 0.007 & 0.234 & 0.690 \\
\hline \multicolumn{7}{|l|}{ Atlantic Ocean } \\
\hline $\begin{array}{l}\text { North } \\
\text { Tropical } \\
\text { South } \\
\text { Mediterranean Sea }\end{array}$ & $\begin{array}{l}743 \\
285 \\
61 \\
131\end{array}$ & $\begin{array}{l}0.55 \\
0.15 \\
0.51 \\
0.28\end{array}$ & $\begin{array}{l}-18.98 \\
-4.61 \\
-17.40 \\
-9.24\end{array}$ & $\begin{array}{l}0.005 \\
0.008 \\
0.013 \\
0.016\end{array}$ & $\begin{array}{l}0.156 \\
0.297 \\
0.449 \\
0.624\end{array}$ & $\begin{array}{l}0.951 \\
0.552 \\
0.963 \\
0.695\end{array}$ \\
\hline \multicolumn{7}{|l|}{ Indian Ocean } \\
\hline $\begin{array}{l}\text { Indian Ocean } \\
\text { Red Sea/Persian Gulf }\end{array}$ & $\begin{array}{l}332 \\
36\end{array}$ & $\begin{array}{l}0.16 \\
0.31\end{array}$ & $\begin{array}{l}-5.31 \\
-10.81\end{array}$ & $\begin{array}{l}0.004 \\
0.014\end{array}$ & $\begin{array}{l}0.135 \\
0.518\end{array}$ & $\begin{array}{l}0.848 \\
0.938\end{array}$ \\
\hline Deep Indian/Pacific & 166 & -0.41 & 14.25 & 0.179 & 6.206 & 0.031 \\
\hline \multicolumn{7}{|l|}{ Pacific Ocean } \\
\hline $\begin{array}{l}\text { North } \\
\text { Tropical } \\
\text { South }\end{array}$ & $\begin{array}{l}751 \\
286 \\
19\end{array}$ & $\begin{array}{l}0.44 \\
0.27 \\
0.45\end{array}$ & $\begin{array}{l}-15.13 \\
-8.88 \\
-15.29\end{array}$ & $\begin{array}{l}0.007 \\
0.006 \\
0.028\end{array}$ & $\begin{array}{l}0.229 \\
0.201 \\
0.996\end{array}$ & $\begin{array}{l}0.834 \\
0.880 \\
0.936\end{array}$ \\
\hline Southern Ocean & 503 & 0.24 & -8.45 & 0.014 & 0.478 & 0.374 \\
\hline
\end{tabular}

$\mathrm{A}$ and $\mathrm{B}$ are two constants, defined for each foraminifera species and for different size [22]. As long as some discrepancies has been observed within the same species, $\mathrm{Mg} / \mathrm{Ca}$ measurements needs to be done on the same morphotype and within the same size fraction (to avoid different partitioning linked to juvenil foraminifera having a faster calcification than the older ones) [23]. These precautions need to be taken also for isotopic measurements on foraminifera species

New studies are on their way to investigate other potential biais to this technic, linked with some dissolution effect on the $\mathrm{Mg} / \mathrm{Ca}$ incorporation, or also some influence of postcrystallization.

At present, taking all these observations into account, uncertainties linked to these reconstructions can be estimated at best around $+/-1.2^{\circ} \mathrm{C}$.

\section{SSS- $\delta^{18} O$ ocean relationship: Solving equation (2)}

Global variations of the isotopic composition of sea water, $\delta^{18} \mathrm{Osw}$, can be estimated thanks to constructed stack of benthic foraminifera $\delta^{18} \mathrm{O}$ (see end of section 2.2). Local variations of $\delta^{18}$ Osw can be estimate with equation (3), measuring $\delta^{18}$ Oc of a specific foraminifera species and having estimated past SST changes (section 3 ).

Once global and local variations in $\delta^{18} \mathrm{Osw}$ have been estimated, past SSS values can be calculated using equation (2). The main problem is that this relationship presents different slopes and intercept values.

The first relationship has been established by Craig and Gordon in 1965, based on measurements done during ocanographic cruises (Figure 2). Since this pionneer work, a lot of measurements have been done and many different relationships, with different slopes, appear for different oceans. As an example, measurements done during Geosecs oceanographic cruises revealed a different relationship than the one established by Craig and Gordon [24] (Figure 2). To fill some gaps in the available data set, some model data have been generated to present the best estimate of the $\delta^{18}$ O-SSS relationship (Table 1) [25,26]. These discrepancies in slopes and in intercept values can be due to local phenomenom, on a spatial scale, as well as on a temporal 
one. On a regional scale, taking the tropical band as an example, fresh water inputs via precipitation could happen close to areas of evaporation, and therefore isotopic values of rainfall and evaporation waters can be very similar. As a consequence, slopes are shallower than the ones in mid or higher latitude. On a temporal scale, seasonnal events such as discharge of fresh water in coastal areas close to a river mouth, or sea ice melwater signals at high latitudes, can influence the salinity- $\delta^{18}$ Osw relationship. On a longer time scale, some studies have demonstrated that the hydrologic cycle, together with the high latitude end-member of precipitation, have obviously changed in the past, as for example during the last glacial maximum [27]. Model results have shown that for small $\delta^{18} \mathrm{Osw}$ changes, there were no correlation between the spatial and the temporal gradient [25]. Important uncertainties still remain on the amplitude of changes in the linear relationship through time.

On a regional point of view, the correlation coefficient $\left(\mathrm{r}^{2}\right)$, linked to each of these local linear least square $\delta^{18} \mathrm{O}$-SSS relationship, goes from very poor value $(0.031$ for the deep Pacific/Indian oceans) to very high values (0.951 for the North Atlantic ocean)(Table 1$)$. As a consequence, confidence in the results of equation (2) depends on the area where the salinity reconstruction takes place.

Within consequent (but still acceptable) uncertainties, quantitative SSS reconstructions can be done and trusted for areas with a high correlation factor, such as for the Artic ocean, North and South Atlantic Ocean, Red sea/Persian Gulf, amongst others. For other areas, as the general tropic areas, for which slopes of the $\delta^{18} \mathrm{O}$-SSS relationship are shallower than for other latitudes (tropical Atlantic and Pacific), errors are larger [25], and quantitative SSS reconstructions need to be taken with caution.

\section{Uncertainties: What to use as a more accurate proxy?}

As seen in section 3 and 4, uncertainties inherent in quantitative SSS reconstructions can be linked to three different steps in the calculation:

1. The accuracy of SST estimations

2. Global $\delta^{18} \mathrm{Osw}$ and salinity changes linked to glacial-interglacial continental ice volume changes.

3. Temporal and spatial decrepancies of the $\delta^{18}$ Osw-SSS relationship (equation (2)).

For the temperatures reconstructions, main uncertainties are between $+/-1.9^{\circ} \mathrm{C}$ and $+/-1^{\circ} \mathrm{C}$, depending on the used method (Table 2) [25]. The most recent studies benefit high resolution or geochemistry developments which drag most of the main temperature uncertainties closer to a best value of $+/-1^{\circ} \mathrm{C}$. Transcript into an isotopic scale, using equation (3), the deduced error on $\delta^{18} \mathrm{Osw}$ estimation is between $+/-0.52$ and $+/-0.23$ per mil.

The source of uncertainty due to glacial-interglacial changes on a global scale has been constrained in the past by many studies, using multiproxy approach and models, which helped to reduce the error bars $[7,8]$. It has reached a mean value for the Last Glacial Maximum (LGM) of about $1.1+/-0.1$ per mil for $\delta^{18} \mathrm{Osw}$, and $1+/-0.05$ per mil for the salinity [25]. Maximum uncertainties are found for period of rapid ice volume changes, as long as it is difficult to estimate the propagation of surface changes down to the deep ocean. It is supposed to be well mixed for period above 1,000 years [25].

For the $\delta^{18}$ Osw-SSS relationship accuracy, the question of its permanence in time is still unsolved. Again, time periods covering rapid ice volume changes, such as deglaciations, present strongest uncertainties than for rather stable climatic periods. For spatial scattering of slopes and intercept numbers, compilation of studied areas are now available and presents, for most linear relationships, uncertainties, confidence intervals and/or correlation factor (table 1) [26]. Estimations of global errors due to these uncertainties range from 1.1 to 0.8 per mil. For tropical area, the range is higher, going from 1.8 to 1.2 per mil uncertainty [25], except for some well defined restricted areas.

Considering all these uncertainties, does paleosalinity reconstruction hold tight?

On a quantitative scale, most of the studies dealing with SSS uncertainties have concluded that paleosalinity signals below 1 per mil can be doubtful [25]. These uncertain reconstructions 
Table 2. Compilation of different case studies focusing on Sea surface salinity reconstruction. For SST estimations, MAT stands for Modern Analog Technic. For SSS estimations, $\delta^{18}$ Osw-ivc* corresponds to the residual $\delta^{18} \mathrm{Osw}$ signal corrected from the global ice volume (icv), and SSS underlines that quantitative salinity reconstructions are presented in the references.

\begin{tabular}{|c|c|c|c|c|}
\hline Location & SST estimations & SSS estimations & Temporal frame & References \\
\hline \multicolumn{5}{|l|}{ Pacific Ocean } \\
\hline $\begin{array}{l}\text { West (Warm pool) } \\
\text { West (South China Sea) } \\
\text { East (Chile) } \\
\text { East (Panama) }\end{array}$ & \begin{tabular}{l|}
$\mathrm{Mg} / \mathrm{Ca}$ \\
Alkenone \\
Alkenone \\
Alkenone $+\mathrm{Mg} / \mathrm{Ca}$
\end{tabular} & $\begin{array}{l}\delta^{18} \mathrm{Osw} \\
\delta^{18} \mathrm{Osw}^{-i v v^{*}} \mathrm{SSS} \\
\delta^{18} \mathrm{Osw}_{\mathrm{ivc}}^{*} \mathrm{SSS} \\
\delta^{18} \mathrm{Osw}^{\mathrm{ivc}}{ }^{*} \mathrm{EEP}\end{array}$ & $\begin{array}{l}1.75 \text { million years } \\
\text { Last climatic cycle } \\
\text { Termination I } \\
\text { Last climatic cycle } \\
\text { (last } 80000 \text { years B.P.) }\end{array}$ & $\begin{array}{l}\text { De Garidel-Thoron et al., } \\
2005 \\
\text { Wang et al., } 1999 \\
\text { Lamy et al., } 2004 \\
\text { Leduc et al., } 2007\end{array}$ \\
\hline \multicolumn{5}{|l|}{ Indian Ocean } \\
\hline $\begin{array}{l}\text { Bay of Bengual } \\
\text { Arabian Sea } \\
\text { South India (Maldives) } \\
\text { Southern }\end{array}$ & $\begin{array}{l}- \\
\mathrm{Mg} / \mathrm{Ca} \\
\text { Alkenone } \\
\mathrm{Mg} / \mathrm{Ca}\end{array}$ & \begin{tabular}{|l|}
$\Delta \delta^{18}$ Osw (pl - bent) \\
$\delta^{18}$ Osw-ivc* SSS \\
$\delta^{18}$ Osw-ivc* SSS in situ \\
$\delta^{18}$ Osw-ivc*
\end{tabular} & $\begin{array}{l}\text { Last two climatic cycles } \\
\text { MIS } 6 \\
\text { Last } 175000 \text { years } \\
\text { Termination I } \\
\end{array}$ & $\begin{array}{l}\text { Kallel et al., } 2000 \\
\text { Malaizé et al., } 2006 \\
\text { Rostek et al., } 1993 \\
\text { Levi et al., } 2007\end{array}$ \\
\hline \multicolumn{5}{|l|}{ Atlantic Ocean } \\
\hline $\begin{array}{l}\text { Low-Latitudes } \\
\text { East (Iberian Margin) } \\
\text { West (Brasil) } \\
\text { West (Brasil) } \\
\text { West (subtropical north gyre) } \\
\text { North }\end{array}$ & \begin{tabular}{|l|} 
Transfer function \\
MAT \\
Mg/Ca \\
Simmax-MAT \\
Mg/Ca \\
MAT + insitu data \\
MAT \\
MAT
\end{tabular} & \begin{tabular}{|l|}
$\delta^{18} \mathrm{Osw}-\mathrm{ivc} * \mathrm{SSS}$ in situ \\
$\delta^{18} \mathrm{Osw}-\mathrm{ivc} *$ \\
$\delta^{18} \mathrm{Osw}-\mathrm{ivc} * \mathrm{SSS}$ \\
$\delta^{18} \mathrm{Osw}-\mathrm{ivc} * \mathrm{SSS}$ \\
$\delta^{18} \mathrm{Osw}$ \\
$\delta^{18} \mathrm{Osw}-\mathrm{ivc} * \mathrm{SSS}$ \\
$\delta^{18} \mathrm{Osw}-\mathrm{ivc} *$ \\
$\delta^{18}$ Osw-ivc*
\end{tabular} & \begin{tabular}{|l|} 
Termination I \\
Last climatic cycle \\
Termination I \\
Termination I \\
$60000-45000$ yrs B.P. \\
LGM \\
Heinrich event 4 \\
Last interglacial
\end{tabular} & $\begin{array}{l}\text { Wang et al., 1995 } \\
\text { Cayre et al., 1999 } \\
\text { Weldeab et al., } 2006 \\
\text { Toledo et al., } 2007 \\
\text { Schmidt et al., } 2006 \\
\\
\text { Duplessy et al., } 1991 \\
\text { Cortijo et al., } 1999 \\
\text { Cortijo et al., } 1997\end{array}$ \\
\hline
\end{tabular}

can't be reasonably taken as boundary condition for ocean and/or climate models. Nethertheless, it can be considered as an estimation of changes on a qualitative point of view.

To avoid the most important uncertainty, linked with temporal and spatial decrepancies of the $\delta^{18}$ Osw-SSS relationship, good qualitative SSS reconstruction can be done by avoiding the final step in the SSS calculation. A simple signal, obtained with a good SST estimation (equation (3)) (better in situ proxies such as $\mathrm{Mg} / \mathrm{Ca}$ ratios), together with a good estimation of a global glacial-interglacial change estimation, lead to a residual $\delta^{18} \mathrm{Osw}$ which represents fairly well past SSS variations, with uncertainties within $+/-0.5$ per mil. In other words, amplitude changes above 1 per mil in the residual $\delta^{18} \mathrm{Osw}$ signal can be considered as true qualitative change in SSS.

\section{Case studies}

According to uncertainty considerations, past SSS reconstructions have been done since the last 17 years, presenting qualitative and/or quantitative results (Table 2). Different approaches, i.e. residual $\delta^{18} \mathrm{Osw}$, corrected or not from ice volume changes (ivc), or calculated SSS, depend on the accuracy of each steps in the calculation.

Because many climatic changes, on orbital or millenial scale, has been recorded in the North Atlantic ocean, many studies have focused on reconstruction of sea surface parameters to understand oceanic imprints of such events. Pionneer studies of Duplessy and his team [15,28-30] have focused on past SSS changes. As described in section 3, a strong confidence in the 'isotopic temperature' reconstruction has been reached for these studies with isotopic analyses of 'modern' planctonic foraminiferal species, compared with sea temperature. Thanks to these calibrations, together with some good estimates of ice volume corrections, $\delta^{18} \mathrm{Osw}$ anomalies have been estimated for the last glacial maximum [15]. Then, using the regular relationship by Craig and Gordon (equation (2)), with a global slope of 0.5 , summer sea-surface salinity reconstruction showed a strong gradient associated with the polar front (Figure 4). For some episodes of strong discharge of fresh water coming from iceberg rafting in the North Atlantic ocean, knowned as Heinrich events, as well as for the penultimate deglaciation, the 


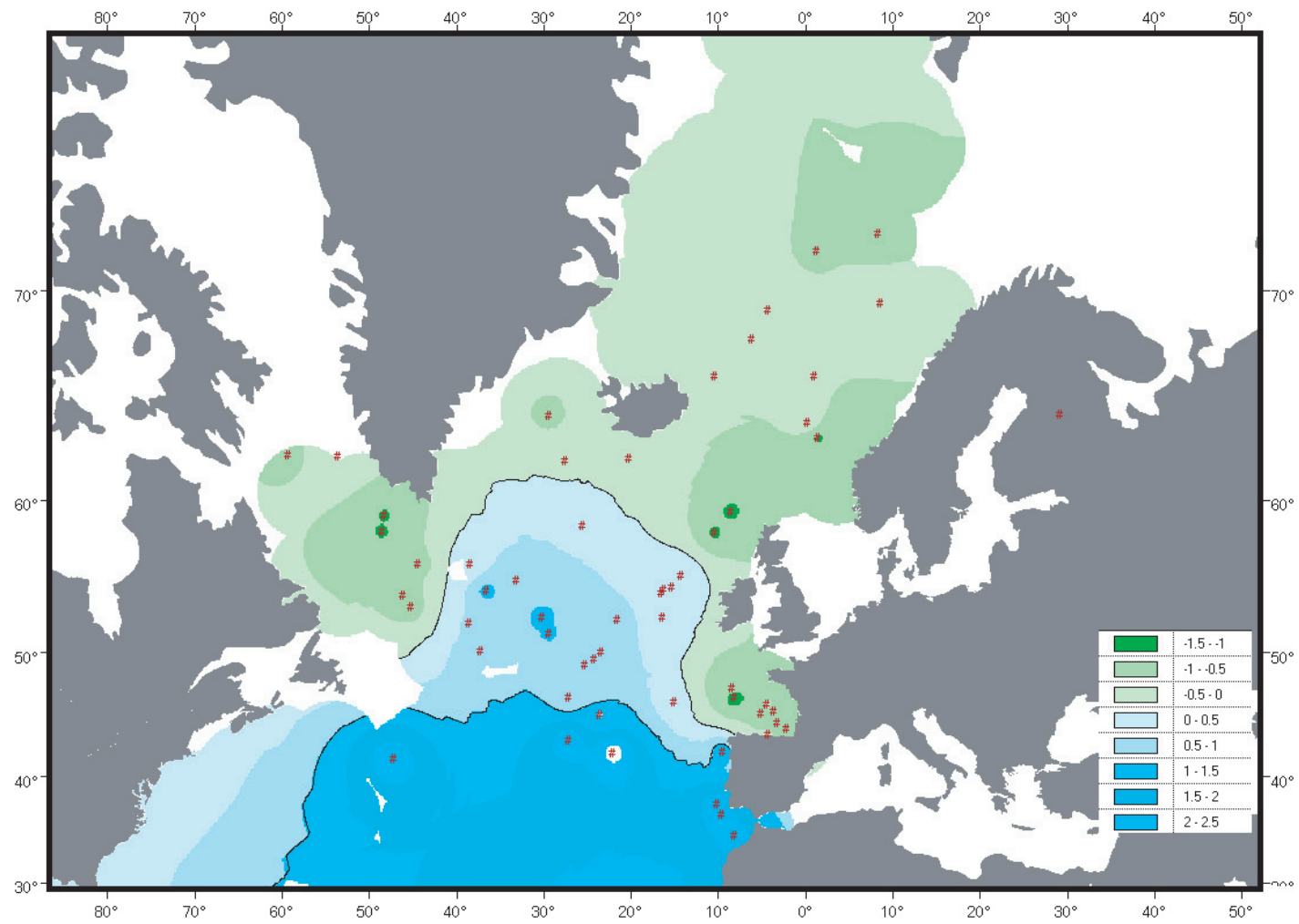

Fig. 4. Reconstruction of summer sea surface salinity for the North Atlantic Ocean during the last glacial maximum (expressed as S-35). Data sets from [15]. Salinity fronts interpolated with Arcview software (acknowledgement to F. Eynaud).

same reconstruction technic has revealed paleosalinities changes of about 1 per mil for such abrupt climatic changes [28-30]. This range in salinity changes holds the limits of confidence defined previously. These quantitative paleosalinity data sets have been used as boundary conditions for several ocean model runs, to investigate surface hydrological changes during Heinrich events and the LGM [31,32].

Two recent studies have focused on specific low latitude areas of the west Atlantic ocean. For both studies, SST estimations are based on $\mathrm{Mg} / \mathrm{Ca}$ measurements on the same foraminifera species used for isotopic measurements. As described previously, such in situ proxies help to reduce uncertainties on SST. For the subtropical North Atlantic gyre, Schmidt et al. presents $\delta^{18} \mathrm{Osw}$ record for some of the most drastic climatic episodes covering the last glacial period, known as Dansgaard-Oeschger events [33]. Millenial-scale surface-salinity enrichments of about 0.7 to 1.5 per mil are detected for two stadials (cold) events at around 48000 and $57000 \mathrm{yrs}$ B.P.. These estimations are using the assumption that present day $\delta^{18}$ Osw-SSS relationship was still valid in the past, which should be taken with care. The author suggests that the slope might have been steeper during glacial time, reducing the reconstruct salinity values below 1 per mil unit [33]. Another study has focused on the brasilian margin, and proposed quantitative SSS reconstructions for the last deglaciation [34]. On a quantitative point of view, two high salinity imprints are recorded for cold periods such as the Younger Dryas period and the Heinrich 1 events, which amplitude are above 1 per mil. Once again, application of the present day $\delta^{18} \mathrm{Osw}$-SSS relationship to the past cast some doubt about the accuracy of such reconstruction. Meanwhile, both reconstructions give probably trustfull qualitative pattern of SSS changes in this area during millenial scale climatic changes.

For the Pacific ocean, few SSS records exist, but cover a wide temporal frame (from 1.7 million years B.P. to the last 25000 years B.P.) (see table 2). Most of these studies present 
$\delta^{18} \mathrm{Osw}$ reconstructions in order to estimate past changes in the surface salinity. Only one ventures to show quantitative SSS values, for the imprints of the last deglaciation on the Chilean margin [35]. For this study, alkenones measurements have been done to estimate SST changes. This alkenone technic is based on measurements done on coccolithophorid chemical remains. Although SST reconstructions using this technic have been thoroughly validated in the past, its application to our SSS reconstruction can still be in abeyance as long as coccolithophorids species might not have the same environmental requirements as foraminifera species. Meanwhile, huge decrease in calculated salinities is recorded between 17.8 to $15.8 \mathrm{kyr}$ B.P., with a amplitude of 5 per mil. As long as this salinity change equals 5 times the acceptable uncertainty range (1 per mil), one can consider this imprint to be a realistic signal, linked with the dynamic of the Patagonian Ice sheet [35].

For the Indian ocean, the main problem lies in the weak $\delta^{18}$ Osw-SSS relationship. The slope is around 0.20 , but with a large standard deviation due to a wide scattering of data points (Figure 2) [36]. As a consequence, except for some well defined areas, quantitative reconstructions are difficult to obtained. Most of the studies present a $\delta^{18}$ Osw signal as a proxy for past SSS $[37,38]$. To reach good confidence in the quantitative reconstruction, precisions need to be obtained for the $\delta^{18}$ Osw-SSS relationship. As seen previously, the correlation factor is quite correct for the Red Sea/Persian Gulf, and can be taken for such calculations. Trusting this good confidence in the $\delta^{18}$ Osw-SSS relationship, Malaizé et al. tempted to calculate quantitative changes in SSS during the penultimate glacial period (at around 175000 years B.P.), a time interval knowned to harbour some strong monsoonal imprints. Rapid decrease of salinity of about 1 per mil is recorded near the Socotran Island during this time, and is linked with fresh water input in the surface ocean, in respons to strong monsoonal rainfall [39]. Anomalies in a $\delta^{18} \mathrm{Osw}$ residual signal from a marine record taken in the gulf of Bengual, for the same period of time, have been also interpreted as a low salinity imprint due to strong indian monsoon [37].

\section{Conclusions}

As long as no geological archives are knowned to directly record sea surface parameters, scientists are bounded to use indirect method to reconstruct past Sea Surface Salinities. Geochemistry of foraminifera shell has revealed a strong potential for this purpose. The $\delta^{18} \mathrm{Oc}$ of the calcitic shell depends on the temperature and on the $\delta^{18}$ Osw of the surrounded waters, itself depending on changes in the continental ice sheets volume and on salinity changes. Some experimental observations have led to the development of mathematical relationship between all these parameters (equations (1) and (2)).

To estimate past SSS, three parameters need to be known: $\delta^{18} \mathrm{Oc}$, SST, and $\Delta \delta^{18} \mathrm{Osw}$, which could be due to local and global phenomenom (such as ice volume changes). The isotopic composition of the calcite is directly measured. Analytical precision is given for each measurements. To estimate past SST, several methods have been developed, from faunistic assemblages to geochemical studies ( $\mathrm{Mg} / \mathrm{Ca}$ proportion in the shell). The best uncertainty on this parameter can be estimate around $1^{\circ} \mathrm{C}$. The global part of $\delta^{18} \mathrm{Osw}$ changes can be estimate with references record, linked with an uncertainty of about $+/-0.1$ per mil. The local part of $\delta^{18}$ Osw changes can be calculated with equation (1), major uncertainties depending on SST error bars. The main error on quantitative SSS reconstruction is linked with the last step of the calculation, i.e. with the $\delta^{18} \mathrm{Osw}-\mathrm{SSS}$ relationship, which presents a wide range of slopes and scattering of data points. For some specific oceanic areas, uncertainties are to high to allowed quantitative reconstructions, and the final step in the calculation must be avoided. For judicious oceanic areas, quantitative reconstructions can be tested. If the amplitude in SSS changes is below 1 per mil, SSS estimations should be taken with caution.

It is a real pleasure to thank the organizers of the ERCA school, Claude Boutron and Michèle Poinsot. The author would also like to thank Frédérique Eynaud for the use of the Arcview software to create figure 4, Gavin Schmidt and Elisabeth Michel for helpfull discussions, and Jean Claude Duplessy for a review of the manuscript. This paper is UMR 5805 EPOC publication $\mathrm{n}^{\circ} 1715$. 


\section{References}

1. T. Wolff, B. Grieger, W. Hale, A. Dürkoop, S. Mulitza, J. Pätzold, G. Wefer, Use of Proxies in Paleoceanography: Examples from the South Atlantic (Springer, Heidelberg, 1999)

2. S. Epstein, R. Buchsbaum, H.A. Lowenstam, H. Urey, Geol. Soc. Am. Bull. 64, 1315 (1953)

3. N.J. Shackleton, N. Opdyke, Quat. Res. 3, 39 (1973)

4. H. Craig, L.I. Gordon, Stable isotopes in Oceanographic Studies and Paleotemperatures (Tongiorgi, CNR Pisa, 1965)

5. Emiliani, J. Geol. 63, 538 (1955)

6. E.J. Rohling, M. Fento, F.J. Jorissen, P. Bertrand, G. Ganssen, J.P. Caulet, Nature 394, 162 (1998)

7. N.J. Shackleton, M.A. Hall, E. Vincent, Paleoceanogr. 15, 565 (2000)

8. C. Waelbroeck, L. Labeyrie, E. Michel, J.C. Duplessy, J.F. McManus, K. Lambeck, E. Balbon, M. Labracherie, Quat. Sci. Rev. 21, 295 (2002)

9. L.E. Lisiecki, M.E. Raymo, Paleoceanogr. 20, 1003 (2005)

10. R.S. Bintanja, W. van de Wal, J. Oerlemans, Nature 437, 125 (2005) doi:10.1038/nature03975

11. J. Imbrie, N.G. Kipp, The late Cenozoic glacial ages (Yale University Press, 1971)

12. J. Guiot, A. deVernal, Proxies in the Late Cenozoic Paleoceanography (Geotop Québec, Canada, Elsevier, 2007)

13. CLIMAP Members, Science 191, 1131 (1976)

14. Kucera, et al., Quat. Sci. Rev. 24, 951 (2005)

15. J.C. Duplessy, L. Labeyrie, A. Juillet-Leclerc, F. Maitre, J. Duprat, M. Sarnthein, Oceanol. Acta 14, $311(1991)$

16. Y. Rosenthal, E.A. Boyle, N. Slowey, Geochim. Cosmochem. Acta 61, 3633 (1997)

17. D.W. Lea, T.A. Mashiotta, H.J. Spero, Geochim. Cosmochem. Acta 63, 2369 (1999)

18. E.A. Burton, L.M. Walter, Geochim. Cosmochem. Acta 55, 775 (1991)

19. A. Mucci, Geochim. Cosmochem. Acta, 51, 1977 (1987)

20. T. Oomori, H. Kameshima, Y. Maezato, Y. Kitano, Marine Chem. 20, 327 (1987)

21. P. Anand, H. Elderfield, M.H. Conte, Paleoceanogr. 18, 15 (2003)

22. Y. Rosenthal, Proxies in the Late Cenozoic Paleoceanography (Geotop Québec, Canada, Elsevier, 2007)

23. H. Elderfield, M. Vautravers, M. Cooper, Geochem. Geophys. Geosyst. 3, 13 (2002)

24. H.G. Ostlund, G. Possnert, J.H. Swift, J. Geophys. Res. 92, 3769 (1987)

25. G.A. Schmidt, Paleoceanogr. 14, 422 (1999) http://data.giss .nasa.gov/o18data/

26. A.N. LeGrande, G.A. Schmidt, Geophys. Res. Lett. 33, L12604 (2006)

27. E.J. Rohling, G.R. Bigg, J. Geophys. Res. 103, 1307 (1998)

28. E. Cortijo, J.C. Duplessy, L. Labeyrie, H. Leclaire, J. Duprat, T.C.E. van Weering, Nature 372, 446 (1994)

29. E. Cortijo, L. Labeyrie, L. Vidal, M. Vautravers, M. Chapman, J.C. Duplessy, M. Elliot, M. Arnold, J.L. Turon, G. Auffret, Earth Planet. Sci. Lett. 146, 29 (1997)

30. E. Cortijo, S. Lehman, L. Keigwin, M. Chapman, D. Paillard, L. Labeyrie, Paleoceanogr. 14, 23 (1999)

31. D. Paillard, E. Cortijo, Paleoceaogr. 14, 716 (1999)

32. A.M.E. Winguth, D. Archer, J.C. Duplessy, E. Maier-Reimer, U. Mikolajewicz, Paleoceanogr. 14, 304 (1999)

33. M.W. Schmidt, M. Vautravers, H.J. Spero, Nature 443, 561 (2006)

34. S. Weldeab, R.R. Schneider, M. Kölling, Earth Planet. Sci. Lett. 241, 699 (2006)

35. F. Lamy, J. Kaiser, U. Ninnemann, D. Hebbeln, H.W. Arz, J. Stoner, Science 304, 1959 (2004)

36. G. Delaygue, E. Bard, C. Roillon, J. Jouzel, M. Stievenard, J.C. Duplessy, G. Ganssen, J. Geophys. Res. 106, 4565 (2001)

37. N. Kallel, J.C. Duplessy, L. Labeyrie, M. Fontugne, M. Paterne, M. Montacer, Palaeogeogr. Plalaeoclim. Palaeoecol. 157, 45 (2000)

38. C. Levi, L. Labeyrie, F. Bassinot, F. Guichard, E. Cortijo, C. Waelbroeck, N. Caillon, J. Duprat, T. de Garidel-Thoron, H. Elderfield, Geochem. Geophys. Geosyst. 8 (2007)

39. B. Malaizé, C. Joly, M.T. Vénec-Peyré, F. Bassinot, N. Caillon, K. Charlier, Geochem. Geophys. Geosyst. 7 (2006)

40. T. de Garidel-Thoron, Y. Rosenthal, F. Bassinot, L. Beaufort, Nature 433, 294 (2005)

41. G. Leduc, L. Vidal, K. Tachikawa, F. Rostek, C. Sonzogni, L. Beaufort, E. Bard, Nature 445, 908 (2007) 
42. F. Rostek, G. Ruhland, F. Bassinot, P.J. Muller, L. Labeyrie, Y. Lancelot, E. Bard, Nature 364, 319 (1993)

43. L. Wang, M. Sarnthein, J.C. Duplessy, H. Erlenkeuser, S. Jung, U. Pflaumann, Paleoceanogr. 10, 749 (1995)

44. L. Wang, M. Sarnthein, H. Erlenkeuser, J. Grimatl, P. Grootes, S. Heilig, I. Ivanova, M. Kienast, C. Pelejero, U. Pflaumann, Marine Geol. 156, 245 (1999)

45. O. Cayre, Y. Lancelot, E. Vincent, Paleoceanogr. 14, 384 (1999)

46. C. Waelbroeck, L. Labeyrie, J. Phys. IV (France) 12, 73 (2002)

47. F. Toledo, K. Costa, M. Pivel, Global Planet. Change 57, 383 (2007) 